\title{
Learning in Support of Governance: Theories, Methods, and a Framework to Assess How Bridging Organizations Contribute to Adaptive Resource Governance
}

\author{
Beatrice I. Crona $^{1,2}$ and $\underline{\text { John N. Parker }}^{3,4}$
}

\begin{abstract}
Humanity faces increasingly intractable environmental problems characterized by high uncertainty, complexity, and swift change. Natural resource governance must therefore involve continuous production and use of new knowledge to adapt to highly complex, rapidly changing social-ecological systems to ensure long-term sustainable development. Bridging and boundary organizations have been proposed as potentially powerful means of achieving these aims by promoting cooperation among actors from the science, policy, and management sectors. However, despite substantial investments of time, capital, and human resources, little agreement exists about definitions and measures of knowledge production and how this is achieved in bridging organizations and there is only meager understanding of how knowledge production and its use are shaped by social interactions, socio-political environments, and power relations. New concepts, methods, and metrics for conceptualizing and measuring learning in support of natural resource governance and testing the conditions under which it can be achieved are therefore badly needed. This paper presents an attempt at a holistic framework to address this, drawing on theory, methods, and metrics from three research areas: knowledge utilization, boundary organizations, and stakeholder theory. Taken together, these provide a solid conceptual and methodological toolkit for conducting cross-case comparisons aimed at understanding the social environmental conditions under which learning in such organizations does and does not occur. We use empirical data to show how the framework can be applied and discuss some of the practical considerations and important challenges that emerge. We close with a general discussion and an agenda for future research to promote discussion around the topic of how to erect systematic comparisons of learning in support of adaptive natural resource governance as it occurs in bridging organizations.
\end{abstract}

Key Words: adaptive governance, bridging organizations, knowledge utilization, learning, networks

\section{INTRODUCTION}

Humanity faces increasingly intractable environmental problems characterized by high uncertainty, complexity, and swift change (Ludwig 2001, Rockström et al. 2009). Adaptive natural resource governance therefore requires continuous learning among researchers, resource managers, and resource users (Folke et al. 2005). Moreover, bridging organizations, i.e., organizations designed to facilitate collaboration and knowledge coproduction among these groups, have been suggested as a way to promote such continuous learning (Carr and Wilkinson 2005, Schultz et al. 2007, Berkes 2009). Despite increasing interest in this topic, however, little is known about the conditions that foster learning and how, specifically, bridging organizations facilitate this process. One reason is that the concept of bridging organizations, as well as the actors, social groups, and collaborative processes involved in them, remains poorly articulated. Existing research also suffers from vagueness surrounding the concept of learning, the processes entailed, and what is actually learned. Put simply, to date there is: (1) no consensus regarding the definition of learning or how to measure it (Armitage et al. 2008, Muro and Jeffrey 2008); (2) poor understanding of how social interactions influence learning (Muro and Jeffrey
2008, Crona and Parker 2011); (3) vague notions of how social environments shape learning (Schusler et al. 2003, Allan et al. 2008, Armitage et al. 2008); and (4) a meager appreciation of how learning is affected by power and conflict dynamics (Allan et al. 2008, Armitage et al. 2008, Muro and Jeffrey 2008). New concepts, methods, and metrics for conceptualizing and measuring learning in support of natural resource governance and testing the conditions under which it can be achieved are therefore badly needed (Reed et al. 2010, Crona and Parker 2011).

Fortuitously, science policy studies offer concepts, methods, and metrics for conceptualizing aspects of learning, measuring it, and understanding when, how, and why it occurs. Work on knowledge utilization, boundary organizations, and stakeholder theory is particularly salient in this respect. Knowledge utilization studies provide a clear means of conceptualizing and measuring some aspects of learning, and for examining how it is affected by different types of social interactions (Armitage et al. 2008, Reed et al. 2010, Crona and Parker 2011). Boundary organization studies examine the importance of different social environments for facilitating learning (Miller 2001, McNie 2007), whereas stakeholder theory offers an unambiguous method of identifying the

\footnotetext{
${ }^{1}$ Stockholm Resilience Centre, Stockholm University, Sweden, ${ }^{2}$ Center for the Study of Institutional Diversity, Arizona State University, Tempe, Arizona, USA, ${ }^{3}$ National Center for Ecological Analysis and Synthesis, Santa Barbara, California, USA, ${ }^{4}$ Barrett Honors College, Arizona State University, Tempe, Arizona, USA
} 
groups involved in learning, assessing their relative levels of power, and the potential for social conflict (Schusler et al. 2003, Allan et al. 2008). Our goal is to relate concepts, methods, and metrics from these research areas as a means of advancing research on learning in support of adaptive natural resource governance as it occurs in bridging organizations. Our aim is to construct a solid conceptual and methodological toolkit for conducting cross-case comparisons aimed at understanding the socio-environmental conditions under which learning in such organizations does and does not occur. This framework is not exhaustive, but should be considered an initial platform on which to build general understanding of these issues and through which generative scientific debate can be modified to capture many of the most critical factors related to boundary organizations and knowledge utilization.

We review the concept of bridging organizations, providing an operational definition and illustrating some of the various forms they can take. We also review research on knowledge utilization, boundary organizations, and stakeholder theory. We operationalize one aspect of learning, i.e., knowledge utilization, and present well-established concepts, methods, and metrics for assessing the environments and social processes that best facilitate the use of scientific information by different actors involved in resource management. We use data and experiences from a case study employing our framework to illustrate how this can be used. Key findings are related and practical considerations and important challenges discussed that can serve as the beginning of an empirical foundation on which to erect systematic comparisons of learning processes across case studies and research sites in the future. We close with a general discussion and an agenda for future research.

\section{BRIDGING ORGANIZATIONS AND THEIR CONTRIBUTION TO ADAPTIVE GOVERNANCE}

Bridging organizations, i.e., organizations linking multiple actors through some form of strategic bridging (cf. Westley and Vredenburg 1991), have been widely cited as promoting learning in adaptive governance contexts (Olsson et al. 2004, Berkes et al. 2005, Eamer 2006, Hahn et al. 2006, Ayles et al. 2007, Olsson et al. 2007, Schultz et al. 2007, Berkes 2009). The concept of bridging organizations emerged to describe organizations linking actors across multiple sectors to solve problems that neither actor would have been able to tackle on their own (Brown 1991, 1993). The bridging organization was seen as "a conduit of ideas and innovations, a source of information, a broker of resources, a negotiator of deals, a conceptualizer of strategies, [and] a mediator of conflicts" (Brown 1991:812). In those early days of the concept, work largely focused on collaborative partnerships across sectors such as NGOs, business, and stakeholders of different kinds (e.g., Gray and Wood 1991, Westley and Vredenburg 1991, Sharma et al. 1994, Selsky and Parker 2005). Although many addressed the role of strategic bridging, less effort was aimed at defining what constitutes a bridging organization. Westley and Vredenburg (1991) came closest by attempting to delineate the bridging role from other types of multiparty collaborations, such as roundtables and task forces, joint ventures, and strategic alliances on the basis of the degree of interpenetration between actors involved. They contend that "bridging is characterized by the presence of a third party [the bridging organization], which is historically separate and distinct in terms of resources and personnel from the 'island' organizations it seeks to link" (Westley and Vredenburg 1991:68). However, bridging organizations come in many shapes and sizes, varying in their degree of formalization, scope, and the number and diversity of stakeholders (Brown 1991, 1993, Westley and Vredenburg 1991, Sharma et al. 1994). Figure 1 graphically depicts where a number of notable bridging organizations exist in relation to the dimensions of stakeholder diversity and the level of organizational formalization. This rough categorization is based on literature, and is merely an attempt to show the wide range in forms that bridging organizations take in relation to these two dimensions.

Fig. 1. Range in forms of bridging organizations based on stakeholder diversity and level of formalization. Stakeholder diversity refers to the heterogeneity of constituents of a bridging organization, as defined by Brown (1991). This categorization is rough and the placement of each organization in the two-dimensional space should be seen as approximate. More work is needed to develop an exhaustive typology of bridging organizations and to fully conceptualize axes along which they vary.

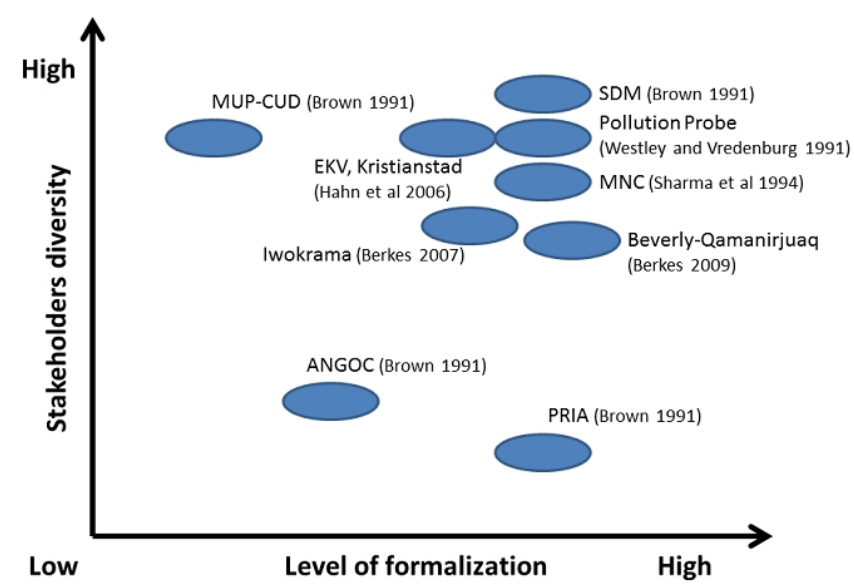

Early work focused on the strategies used by bridging organizations to achieve their goals (Lawrence and Hardy 1999, Stafford et al. 2000), as well as their underlying motivations for bridging between 'islands' (Westley and Vredenburg 1991, Sharma et al. 1994). Through its 
incorporation in the adaptive governance literature the concept of bridging has changed somewhat, placing increasing importance on learning and collaborative governance processes (e.g., Folke et al. 2005). The goal of bridging organizations in adaptive environmental governance is principally to provide an arena for learning as well as a space where trust building and conflict resolution can be achieved and where bridges can be built between science, other forms of knowledge, government, and nongovernmental actors (Olsson et al. 2004, Berkes et al. 2005, Eamer 2006, Hahn et al. 2006, Ayles et al. 2007, Olsson et al. 2007, Schultz et al. 2007).

Despite the central focus on learning, both learning and the processes by which it occurs remain vaguely defined in much of the adaptive governance literature (see Armitage et al. 2008, Reed et al. 2010 for a recent critique). Critics point out that the vagueness stems from the fact that learning occurs in many ways, from loosely defined social networks (cf. Crona and Bodin 2006, Bodin and Crona 2009) to more or less formalized arenas, such as bridging organizations (Hahn et al. 2006) or communities of practice (Wenger 1998). Conceptualizations of learning in these different arenas therefore draw on various fields including adult education, organizational development, and business management (see Armitage et al. 2008 for a review), and focus on learning at scales ranging from the individual to the collective. This has made assessments and comparisons of learning across cases difficult, and has hindered the development of systematic metrics of learning and understanding of the socio-environmental conditions that promote or impede effective learning for adaptive governance. Given the lack of a generally accepted definition of bridging organizations, and our aim to delineate a framework for systematically investigating such organizations, we propose a working definition that builds on Westley and Vredenburg (1991): bridging organizations are organizations that link diverse actors or groups through some form of strategic bridging process. They are organizations in their own right and are relatively distinct in terms of resources and personnel from the parties they seek to integrate. This degree of formalization distinguishes bridging organizations from informal social networks revolving around a few individuals that can also provide a bridging function in adaptive governance contexts (e.g., Olsson et al. 2006).

\section{LESSONS FROM SCIENCE POLICY STUDIES}

Knowing how to best promote learning in bridging organizations will require conducting systematic, cross-case comparisons of learning and the social processes associated with it across diverse bridging organizations. Such comparisons will require a clear definition of the type of learning occurring and a systematic method for measuring the extent to which it occurs. They will also require methods and metrics for measuring those social processes and environments that are known to be associated with learning but that have received limited attention in bridging organization and adaptive governance literatures. These include: (1) social relationships and networks; (2) social environments; and (3) power and conflict. Drawing on concepts, methods, and metrics from science policy studies, we provide an operational definition of learning focusing on one aspect of this complex process, i.e., knowledge utilization, and a clear method for its measurement. We also conceptualize and identify well-established metrics for measuring social processes and environments known to be important for knowledge utilization. Three areas of science policy studies, each outlined in turn, are important in these respects.

\section{Knowledge utilization studies}

Learning has been studied from a multiplicity of perspectives, from formal education (Piaget 1985) to social learning (Bandura 1977, Pahl-Wostl et al. 2007, 2008). However, as treated in adaptive governance contexts learning remains vaguely defined, confusing the term and hindering cross-case comparisons. A clear, consistent, and operational definition of learning in adaptive governance is therefore needed. Two main approaches present themselves. The first is to measure learning as the extent to which actors or organizations involved in adaptive governance add new information to previously existing stocks of knowledge. Defining and measuring learning in this way would likely require incorporating transformative and experiential learning theory (e.g., Kolb 1984, Mezirow and associates 2000), and its assessment would be time consuming and context specific. Moreover, it misses one essential point of adaptive governance, namely, if what is learned is used to better inform natural resource governance.

For these reasons, we focus on one specific aspect of learning in adaptive governance, that is, knowledge utilization. Knowledge utilization studies examine how knowledge is transferred from the environments in which it is created to environments where it can be used to improve human wellbeing (Backer 1991, Gano et al. 2007). From this perspective, learning can be defined as the extent to which knowledge arising from social interactions occurring within bridging organizations is used to inform natural resource governance policies and practices. Although this approach is delimited in only assessing one subset of the learning process, it has the merit of focusing on the outcome of greatest interest, i.e., the use of coproduced knowledge to improve natural resource management, and is readily applicable across diverse sets of bridging organizations. Furthermore, a well-established scale exists for measuring knowledge utilization, developed by Knott and Wildavsky (1980) and modified by Landry et al. (2003) and Crona and Parker (2011; see Appendix 1.1). Knowledge utilization is assessed as a progression of six stages: reception, cognition, discussion, reference, effort, and influence. This scale conceptualizes utilization as a process "usefully conceived as stages in which each is a link in the chain of utilization" (Knott and Wildavsky 1980:545). The 
scale is multiplicative as each stage is assumed to be more important than the previous for achieving knowledge utilization, and thus is accorded progressively more weight. The stages are "meant not only to capture the extent to which information is processed cognitively by the policy-makers but also its consequence in the policy process [emphasis added]" (Webber 1992:21). Such a scale is relevant for understanding knowledge utilization in adaptive governance because decisions to incorporate new understanding do not usually depend on a single event but on a series of findings or interactions converging toward one direction (Booth 1990, Lomas 1997, Rich 1997). Widely adopted, such an outcome metric would represent an important first step in allowing for a cross-case comparison of this aspect of learning in support of adaptive governance.

Knowledge utilization studies also provide insights into the ways in which social relationships affect learning. Landry et al. (2003) provide a useful overview of socio-organizational factors mediating knowledge transmission between actors. First, 'two-communities' explanations assume that cultural differences between actors in terms of the types of qualities of knowledge desired can hinder knowledge utilization (Frenk 1992, Oh and Rich 1996, Gano et al. 2007). For example, cultural differences between policy makers and academic researchers are commonly conceptualized in terms of the different norms and values they hold regarding the knowledge transfer process (Caplan 1979, Oh and Rich 1996). Researchers often value basic scientific research, methodological rigor, and traditional methods of knowledge dissemination, i.e., academic journals, whereas actors like policy makers or resource managers typically value research designed to meet their specific needs and nontraditional dissemination strategies, e.g., face-to-face meetings. Second, 'organizational interests' explanations suggest that knowledge utilization increases when knowledge production incorporates the needs of end user groups rather than, for instance, focusing on advancing basic scientific understanding (Frenk 1992, Orlandi 1996). Finally, 'social interactions' explanations contend that interaction, or lack thereof, between actors is a major factor determining knowledge utilization (Frenk 1992, Oh and Rich 1996). Knowledge utilization is therefore expected to increase as meaningful interactions between actors increases.

How can the effects of these social processes and relations on knowledge utilization be systematically assessed and compared across cases? Metrics and methods from knowledge utilization studies, social network analysis, and qualitative analysis provide some starting points. Based on research by Gano et al. (2007), we developed quantitative survey items for determining the extent to which cultural differences exist between social groups involved in natural resource governance with respect to the importance of scientific merit, experimental design, interpersonal contacts, and knowledge dissemination strategies (see Appendix 1.2). Independent samples t-tests can be used to test for statistically significant differences between groups, and the extent to which groups differ along one or more of the 'cultural axes' can be quantified and regressed on the knowledge utilization scale. Other potentially useful scales can be found in Lach et al. (2003) and Steel et al. (2006, 2010). To our knowledge, no scale has been designed to capture the extent to which organizational interests between actors are aligned and how this affects knowledge production and use. We adopt a qualitative approach to assessing divergences in organizational interests, whereas Landry et al. (2007) used six quantitative measurements as proxies to examine the influence of such divergences on knowledge utilization. More work is needed to develop a general quantitative metric of divergences in organization interests, and as with all of the above social relationships, quantitative metrics are most revealing when combined with more case-specific forms of qualitative inquiry.

In terms of studying social interactions, social network analysis is the most well-established method to quantitatively measure the number, types, and intensity of social interactions between actors and social groups. Combined with regression and other forms of statistical analysis, network analysis allows for assessments of the extent to which different amounts, types, and strengths of social interactions correlate with the utilization of knowledge to inform natural resource governance.

\section{Boundary organization studies}

Boundary organizations are formal institutions organized at the intersection of divergent social groups to broker or mediate interactions across a border of diverse purposes, incongruent values, and potential mutual incomprehension (Guston 2001, Hackett and Parker 2012). They resemble bridging organizations in that they are concerned with linking actors across domains, disciplines, and hierarchical levels, facilitating communication and enhancing some form of collaborative output. They differ from bridging organizations in that they have traditionally had a more narrow focus on the science-policy interface, and have more clearly defined organizational arrangements, such as structures for accountability. The concept of boundary organization is grounded in principal-agent theory in economics, and the value of its research for understanding learning in support of natural resource governance lies in its identification of the types of social environments, roles, and practices that best facilitate collaboration between these groups and knowledge utilization for practical purposes. Of major importance in this respect is the provision of incentives to all groups involved in the collaborative process, as well as designing specific lines of accountability between each group and the organization (Guston 1999, Cash et al. 2003). Such incentives help motivate participation while the creation of accountabilities helps ensure that the organization will not be unduly influenced by 
any one group. If successful, this results in a less politicized collaborative environment wherein members of different social groups working to coproduce knowledge can meet on relatively neutral grounds and more effectively promote the utilization of knowledge to inform decision making. Boundary organization studies have also emphasized the creation and use of boundary objects to facilitate knowledge utilization. These are objects, e.g., models, classification systems, or interactive maps, allowing members of different communities to interact and coordinate their efforts despite their sometimes divergent perceptions of the object (Star and Griesemer 1989, Fujimura 1992, Cash et al. 2003). Finally, liaisons and brokers who can guide the process of knowledge coproduction and utilization have also proven to be important (Quay 2004, Yip et al. 2008, Morse 2010), as they have in the context of bridging organizations (Olsson et al. 2004, Schultz et al. 2007).

In terms of measurements and metrics, boundary organization research suffers from some of the same limitations as work on learning in adaptive governance, lacking systematic measurements of key processes, variables, and outcomes, treating knowledge production and transfer as acts rather than processes, and rarely engaging in theory building and crosscase comparisons (cf. Miller 2001, McNie 2007). More work is required to operationalize and systematically test elements of the theory of boundary organizations. Nevertheless, important advances are being made that could enhance the study of bridging organizations. Qualitative assessments of how these organizations provide dual accountabilities and incentives offer the richest method of assessment, including in-depth interviews with bridging organization members regarding these issues, and ethnographic observations of interactions between and among them (e.g., Crona and Parker 2009). Standardized quantitative assessments of accountabilities and incentives have yet to be developed, but would also be an important step forward in systematizing research on bridging organization performance.

Two main methods have been used to assess the efficacy of boundary objects for enhancing knowledge utilization. One approach has been to conduct in-depth interviews with relevant social groups regarding boundary object efficacy (Crona and Parker 2009). More recently, White et al. (2010) developed a multimethod framework for assessing how different social groups perceive the credibility, relevance, and legitimacy of boundary objects ${ }^{[1]}$. This approach stems from Cash et al. (2003) who outline the importance of assessing the potential for knowledge utilization as a function of these three characteristics, whereby credibility refers to the scientific adequacy of any piece of knowledge produced, relevance refers to the pertinence of knowledge to the needs of end users, and legitimacy refers to whether the production of information is respectful of stakeholders' divergent values and fair in its treatment of opposing views and interests. White et al.'s (2010) method is valuable because it provides formal presentations of boundary objects to user groups and mixes qualitative and quantitative metrics to assess both the variety and strength of attitudes regarding the boundary objects, as well as quantitative data on the extent to which each group is positive, negative, or neutral with respect to its perceptions of credibility, relevance, and legitimacy.

Finally, formal social network analysis provides a powerful means by which to test for the existence of important liaisons and brokers between social groups involved in learning to support adaptive governance. We use network survey data (see Appendix 1.3, 1.4 for survey items) to create network graphs, identify key brokers between social groups, and examine the importance of occupying such central positions for facilitating knowledge utilization. In-depth interviews can and should be used to complement and validate such quantitative analyses.

\section{Stakeholder theory}

With origins in organizational management, stakeholder theory was originally developed to identify, analyze, and manage relations among the stakeholders served by a corporation (Freeman 1984). More recently, stakeholder theory has been used to understand how to manage multisector collaborations aimed at linking knowledge producers to public policy makers (Rod and Paliwoda 2003, Parker and Crona 2012). Stakeholder theory is valuable for understanding learning in bridging organizations because it provides an unambiguous method by which to assess each social group's relative level of saliency with respect to the organization, that is, each group's ability to demand that the bridging organization meet its needs before those of others. It thus allows for analysis of power and conflict in relation to learning and adaptive governance. Bridging organizations operate at the intersection of diverse social groups wielding differential abilities to demand that their needs be met, and so understanding which groups wield greater abilities to influence bridging organization activities is an important consideration when managing relations among them and understanding when and how knowledge gets created and utilized. A group's relative saliency in relation to a bridging organization is a function of the extent to which it is viewed as powerful, legitimate, and urgent by the organization (Mitchell et al. 1997). Power refers to the group's ability to marshal coercive, utilitarian, or normative means to impose its will on the relationship. Legitimacy refers to the perception that the group and its actions are appropriate within a system of norms, values, and beliefs. Urgency refers to the extent to which (1) a relationship or claim is of a time-sensitive nature, and (2) when that relationship or claim is important or critical to the stakeholder. The various possible combinations of stakeholder power, legitimacy, and urgency result in seven possible types of stakeholders. Stakeholder salience is predicted to be low when only one attribute is believed to exist, moderate where two are believed to exist, and high where all three are present. 
We used multiple methods, i.e., in-depth interviews, ethnographic content analysis, and documentary analysis, to assess the relative levels of power, legitimacy, and urgency among stakeholder groups collaborating within Decision Center for a Desert City (hereafter, DCDC: http://dcdc.asu.edu/ ). Although standardized quantitative measures of these relations would also be valuable and should be constructed, their complexity will likely require them to be complemented by qualitative assessments.

Figure 2 outlines the conceptual framework that results from the integration of the different literatures examined here. This forms the basis for the next section describing how the methods and metrics outlined above can be applied in an empirical study of bridging organizations and their role in promoting knowledge utilization.

Fig. 2. An integrated conceptual framework for studying knowledge utilization in bridging organizations. The figure shows the approaches to studying learning in bridging organizations proposed in our research (middle column) and the suggested metrics associated with the operationalization of each (right column). The arrows indicate the research area from which the methods and metrics are drawn and how these feed into each of the two suggested approaches. The vertical arrow indicates that the two approaches are mutually complementary and should be pursued in tandem.

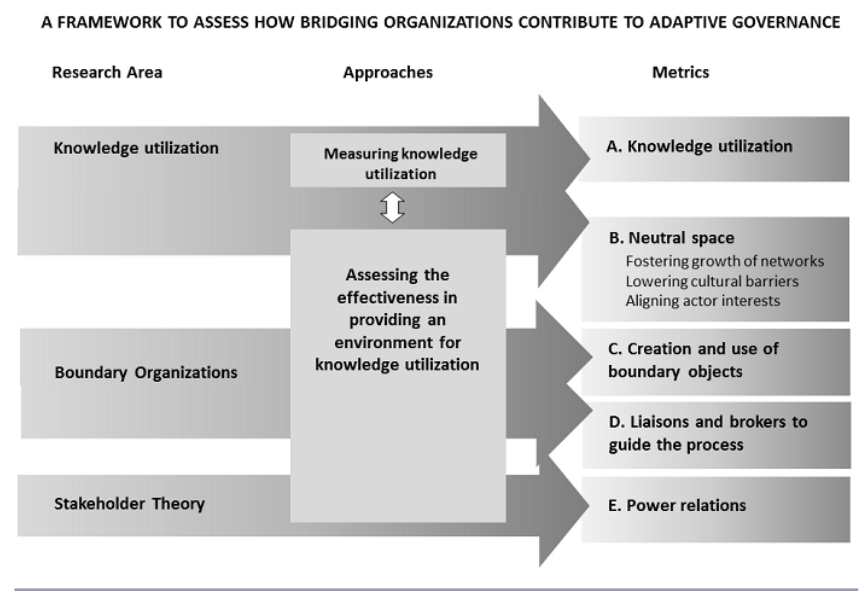

\section{STUDYING LEARNING IN SUPPORT OF ENVIRONMENTAL GOVERNANCE: THE CASE OF THE DECISION CENTER FOR A DESERT CITY}

\section{Case description}

Arizona State University's DCDC serves as our case study to illustrate how the different theories and metrics outlined above can be applied empirically. Founded in 2004 through the U. S. National Science Foundation's program on Decision Making Under Uncertainty, DCDC was explicitly designed as a bridging/boundary organization with the goals of building "a new model of science and policy engagement that allows decision makers (including practitioners) and scientists to collaborate on important research questions and experiment with new methods" (DCDC project summary, unpublished manuscript). As such, the actors participating in DCDC come from a variety of social spheres including scientists, policy makers, water managers, and water user groups. DCDC is a formalized entity but has only a few full-time staff. The vast majority of participants collaborating in this bridging organization are employed by outside organizations such as traditional university departments, city and state water agencies, and for-profit water management companies. These actors come together in different temporary constellations to address specific issues for water governance. DCDC operates in the highly politicized context surrounding water management and urban development in the arid Southwestern United States. The Phoenix metropolitan area is one of the fastest growing urban centers in the U.S., and tensions between urban development, economic growth, and environmental sustainability arise continuously (Gober 2006, Gober et al. 2010). Finding ways to contribute to adaptive governance in light of potential climate change is therefore a top priority for DCDC and this made it an interesting site to test our methods for studying the determinants of knowledge utilization in adaptive environmental governance. The case we present draws on material from 33 in-depth interviews, ethnographic observations, documentary content analysis, and a network and attitudinal survey of participants in DCDC ( $n=107$; see Appendix 1).

All interview, documentary, and observational data were analyzed using ethnographic content analysis, an iterative, reflexive method designed to uncover meaningful concepts and variables and verify relationships among them (Altheide 1996). This method was facilitated by the use of qualitative analysis programs (Atlas.ti and QWeftQDA) to systematize subject coding, sort and index interviews, observations, and documents, and allow for word searches across documents. Thematic coding categories were collapsed or expanded according to their relevance as coding progressed. The authors coded all data independently, cross-checking results to test for intercoder reliability. Statistical analyses were run using SPSS 17.0 and Ucinet (Borgatti et al. 2002).

\section{Social interactions and knowledge utilization}

Our first aim was to measure if DCDC bridging activities were resulting in the use of new types of scientific information related to water management by water policy makers and managers. Knowledge utilization was measured using a modified version of the established scale of Knott and Wildavsky (1980; Fig. 2A, Appendix 1.1). Ideally, knowledge utilization should be measured not only in terms of the knowledge that science provides to policy, but also in terms of the insights that policy makers lend to scientific work. For 
the purposes of this study, however, we focused on the use of scientific information by policy makers and resource managers. We regressed each policy maker or water manager's knowledge utilization score against two measures of social interaction obtained through our network survey ${ }^{[2]}$. This included: (1) the total number of contacts each policy maker had with DCDC researchers; and (2) the total number of other policy makers with whom they communicated about DCDC research. The analysis was conducted in two steps to test the independent effects of these two types of social interaction (Appendix 2, Table2.1). Figure 3 depicts the network graphically.

Fig. 3. Network of interaction between researchers and policy makers participating in the bridging organization (Decision Center for a Desert City [DCDC]). Researchers are represented by squares and policy makers by circles. The size of the node indicates its relative betweennesscentrality (a formal network measure), which in turn is an indication of how well this actor connects other actors in the network. Actors with a high betweenness-centrality can be said to play a potentially important role as liaisons and brokers in a network of collaborating stakeholders.

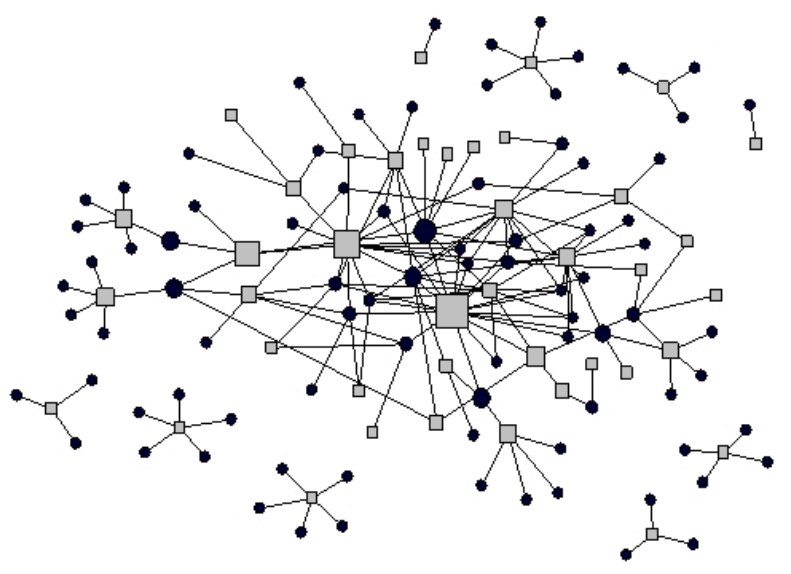

Policy makers with greater numbers of contacts with DCDC researchers were significantly more likely to use DCDC work to inform their natural resource governance work $\left(R^{2}=0.104\right)$. Furthermore, when these policy makers spoke with greater numbers of other policy makers about DCDC research they were more likely to use it to inform their work. The addition of this variable to the statistical model more than doubled its explanatory power $\left(\mathrm{R}^{2}=0.260\right.$; see Appendix 2 for more detail on the model). Two different types of social interaction were therefore positively, and independently, associated with knowledge utilization by policy actors. It appears that policy makers with greater numbers of connections to bridging organization researchers are more likely to use it because of greater exposure and access. Their working knowledge of DCDC research may also make them more likely to view it as salient, credible, and legitimate, further increasing their likelihood of accessing and using it (Cash et al. 2003).

Furthermore, policy makers who discuss knowledge coproduced within DCDC with greater numbers of other policy makers are also more likely to use it. This probably derives from the fact that in their discussions with peers they are more likely to become aware of relevant findings, and also that these discussions may serve to increase their perceptions of the legitimacy and credibility of the research as they realize that other colleagues trust and use organizational data and findings. These findings are novel and important. Though many have suggested that network ties matter for learning and knowledge utilization in bridging organizations (Folke et al. 2005, Hahn et al. 2006, Olsson et al. 2007), this is the first analysis to demonstrate this empirically. Moreover, it is the first to discover that ties between policy makers also matter, strongly suggesting that the external reputation of the organization among actors involved in natural resource governance can shape the ability of these organizations to achieve their goals.

\section{Social environments}

Given existing research in knowledge utilization studies and boundary organizations, we also examined how the creation of a depoliticized space and boundary objects shaped knowledge utilization, and the role of liaisons and brokers in forwarding the process. We did so by examining the social environment that DCDC created and its role in promoting conditions conducive for learning (cf. Kolb 1984, Rist et al. 2007).

\section{Creating a neutral space}

The creation of a politically neutral space can serve both to facilitate the growth of social networks focused on a particular topic and to lower cultural barriers and align the interests of diverse social groups collaborating within the context of the bridging organization (Fig. 2B). We examined the extent to which such neutrality fostered the growth of social networks via open-ended, in-depth interviews. Within DCDC, the primary activity providing such a space and in which these social groups interact are 'water briefings,' meetings organized by DCDC in which researchers and policy makers meet to discuss water related issues. Policy makers consistently pointed to these meetings as important for making ties within the water community, with $62 \%$ claiming that their ties in the water community had expanded as a result of their participation in the organization and all citing water briefings as the main mechanism by which this came about. The water briefings brought together both academic researchers and policy makers and were designed to create a depoliticized space that could facilitate nonconflictual interactions among these groups. The briefings, as well as other events organized 
by DCDC, made participants aware of others involved in water policy and management and exposed them to the perspective of these other actors.

To assess the degree to which such meetings resulted in lowered cultural barriers between researchers and policy makers, we used the quantitative metrics described above to test for differences along several cultural axes (Appendix 1). We found few significant differences. Independent samples ttests indicated no significant difference between researchers and policy makers regarding the importance of (1) scientific merit, (2) interpersonal contacts, and (3) dissemination strategies for knowledge utilization. Perceptions of the importance of (4) experimental design differed only slightly between the two communities, with policy makers perceiving this to play a somewhat greater role for knowledge utilization ( $p=0.02$; two-tailed). Combining these results with the qualitative analysis we conclude that the increased interaction among different groups, and the increased networking as a result of DCDC organized events, has served to better align the interests of the different social groups participating in DCDC and lower cultural differences between them. Where possible, such measures should be undertaken at the inception of the bridging organization and at regular intervals thereafter so as to better assess these effects over time and in relation to important events.

\section{Boundary objects as a means to align interests}

One way in which DCDC worked deliberately to increase credibility, relevance, and legitimacy (sensu Cash et al. 2003), and thus promote knowledge utilization, was through the use of boundary objects (Fig. 2C). The primary boundary object was WaterSim, a regional-scale simulation model of water supply and demand integrating climate, land use, and population growth data to examine future water use scenarios (see White et al. 2010). WaterSim was used as a tool to engage both water managers and policy actors. Although the process eventually led to an increased alignment of interests the road there was not straight. The main issue arising was that policy makers felt they were not included in the development of WaterSim early enough to contribute to its design. This affected the legitimacy of the boundary object. In addition, when they were eventually invited to contribute the temporal and spatial scales of the model were not perceived as relevant or salient, a problem known to decrease opportunities for learning. This was particularly the case for water managers who operate on short time scales and smaller geographic areas than those on which the model operates. The following views expressed by DCDC participants from both the academic and management side portray this well.

The people who make real-world management and policy decisions work on a different time scale than many of my colleagues and I work on. We work in months and years to figure out things. They need to know what's going on next week (DCDC leader).
The timescale issue, the [DCDC water] model flow, the groundwater models are [on] monthly, yearly time increments, where our actual distribution system and wells operate on a minute-by-minute basis (City water manager).

[W]ater managers I know look at [WaterSim] and say, "Well, yeah. But that assumes that water crisis enfolds over a decade or more, that we didn't make any adjustments during the decade. We know how to react. We've been doing this for 100 years. We would be making changes throughout the period. So your model is telling me nothing I didn't know. I understand if we don't watch it and the amount of water falling in the watershed is going down and the population is going up, we're going to have a problem ... I didn't need a computer model to tell me that." [pause] What ... I don't think has happened yet is I don't think the water manager types believe WaterSim well enough to go in there and say, "Okay, well run it for two years and let me tell you what I would do. And then let's run it for another two years and let me tell you what I would do. And then let's run it for another two years. "I don't know that they have enough faith in the way the model is constructed to even be willing to do that (Water policy actor).

This tension also led to a feeling of distrust in the model itself and the data on which it was based. Understanding this dilemma, the modelers and the leaders of DCDC made a concerted effort to remedy the situation. They engaged the same actors in a new round of discussion around the model and offered to customize and down-scale it to a level where it could be more useful to practitioners. This increased the relevance of the boundary object and improved the learning process, as illustrated by the following statement by a water manager.

\section{[I]ts assumptions and inputs are largely inaccurate - there are some real problems with the model in that regard. But I think that the model has a large amount of value and that's one of the reasons we were willing to partner with [DCDC modeler] and actually try to create a little [name of city] box that was more accurate and that works (City water manager).}

Because of a belief among both academics and more regionally oriented policy actors of the importance of accounting for the regional scale, the regional model was maintained in parallel with the efforts to customize the boundary object for practitioners. This strategy resulted in improved credibility, relevance, and legitimacy of the boundary object (WaterSim), increasing the likelihood that it will be used by relevant stakeholders to inform adaptive water governance. The way in which DCDC maneuvered to resolve these issues of credibility, relevance, and legitimacy demonstrates its ability to adjust its activities to support learning. It also indicates the 
importance of constant negotiation of tensions for more positive learning outcomes.

\section{Liaisons and brokers}

Several individuals, from both the scientific and policy community, played key roles in devising strategies to resolve these issues, and to facilitate the process of mutual learning among actors (Fig. 2D). The leaders of DCDC were instrumental in this respect but they were also assisted by others. A key player was a person specifically recruited to DCDC to function as a liaison.

He's a boundary player. Classic... He has a Ph.D., he's done some publishing. He's spent his life as a bureaucrat in the [City of Phoenix] Department of Water Resources. He has a rolodex that's very thick ... we see him as a facilitator of relationships, of networks ... He was hired to do that, he does that explicitly (DCDC leader).

This individual had both an academic background as well as a significant career within the water policy community and therefore commanded respect within both communities. His ability to broker between different social spheres proved to be important for DCDC's efforts to rekindle the process around WaterSim after the initial failure, and also to increase awareness of the organization among the water policy community. A similar role was played by another senior policy actor who served as a bridge between the water policy and the urban development community. The integration between water and development sectors in a fast growing urban area like Phoenix is essential for sustainable water governance in the long term. The network analysis conducted can also be used to reveal these key players by examining actors occupying key positions in the network of communication (Fig. 3). Actors with high betweenness-centrality hold potentially important brokering roles. Finally, several individuals working as administrative support within DCDC played instrumental roles in connecting actors and keeping information flowing between the social groups collaborating in the bridging organization. This fact was corroborated independently via interviews and social network analysis.

\section{Negotiating power relations}

The ability to promote learning is shaped by power and conflict relations among the stakeholders served by the bridging organization (Fig. 2E). Bridging organizations exist at the intersection of highly diverse social groups, e.g., academic researchers, policy makers, resource users, and funding agencies, seeking potentially irreconcilable demands from the organization. For instance, DCDC serves both the academic community and water policy makers. Although the former values DCDC contributions to basic scientific understanding, the latter value the production of applied research speaking to their immediate needs as policy makers and resource managers. This produces enduring sets of value tensions that organizational leaders must negotiate, such as the tension between academic autonomy and professional consultancy. To further complicate matters, bridging organization stakeholders often differ in their ability to demand that the organization meet their needs before those of other stakeholders. Returning to our example, DCDC is a bridging organization housed within a major research university. The result is that despite the fact that DCDC is in many ways a nonacademic entity, the academic community enjoys a higher level of saliency than do policy makers because they are viewed as more legitimate, their claims more urgent, and so they wield greater coercive power over bridging organization activities. This has, at times, stymied DCDC's ability to allocate sufficient resources to working with policy makers to help inform natural resource governance (Crona and Parker 2009). Conflicting interests and the saliency differentials that determine which interests are met can undermine the learning process that contributes to adaptive governance. As a city water manager noted,

\section{[DCDC's] pressure is to publish, and so I think you 're just inherently going to come up with different products ... academics have to look at things theoretically, especially to get published ... we [policy makers] got [sic] politics and you can have the best theoretical model [laughs], [but] it's applicability to the real world is always going to be inherently limited (City water manager).}

It is not the case, however, that such power differentials will permanently derail all attempts at promoting learning. Rather, reconciliation of competing demands requires strategic timing and innovative strategies for meeting the needs of both groups simultaneously. In terms of strategic timing, DCDC leaders first worked to satisfy the most urgent demands of academicians before returning to work with the water policy community. Effectively managing power differentials and conflicting demands required engaging in an initial period of prioritizing the more powerful stakeholders' needs, followed by a period of meeting the needs of the less powerful stakeholder. In terms of innovative strategies, DCDC developed the water flow model (WaterSim) that was of a sufficiently broad scale to allow basic scientific research on climate change while also producing scaled-down versions specific to local water districts. This tactic allowed for meeting the needs of both the research and policy communities simultaneously, satisfying both while promoting knowledge utilization in adaptive resource governance.

\section{DISCUSSION}

We have defined bridging organizations as organizations linking diverse actors or groups through some form of strategic bridging process and that are more or less distinct from the parties they work to link. They are analytically distinguishable 
from informal networks working to promote learning in support of adaptive governance through their degree of formalization. Given the increasing interest and substantial investments of capital and human resources in such organizations, surprisingly little agreement exists about definitions and measures of knowledge production and use in bridging organizations (Armitage et al. 2008; Crona and Parker 2011). Furthermore, there is only a meager understanding of how knowledge utilization is shaped by social interactions (Miller 2001, McNie 2007), socio-political environments (McNie 2007, Allan et al. 2008), and power and conflict relations (Rod and Paliwoda 2003, Schusler et al. 2003, Hackett and Parker 2012). Addressing this knowledge gap requires systematic assessments of the conditions under which bridging organizations contribute to learning in adaptive governance contexts. We have proposed a synthetic theoretical and methodological framework for conducting such assessments that provides an operational definition of learning focused on what is arguably the most important aspect of the learning process, knowledge utilization, and which relies on a suite of well-established concepts and metrics for measuring bridging organization characteristics and the social processes and environments that characterize them (Fig. 2).

Using the case of DCDC, an organization designed to bridge academic and water governance groups, we have shown how this framework can be applied in practice. Combining formal social network analysis with our suggested scale of knowledge utilization, we found that different numbers and types of social interactions can have significant, independent effects on the use of scientific knowledge in natural resource governance. Policy makers with greater numbers of contacts with academics participating in the bridging organization were more likely to utilize information produced within DCDC to govern water resources, as were policy makers who discussed bridging organization research with other policy makers. This supports work in public policy demonstrating the importance of embeddedness of actors in social networks of peers for knowledge utilization (Nahapiet and Ghoshal 1998, Adler and Kwon 2002). Furthermore, the fact that greater numbers of contacts among policy makers had an independent positive effect on knowledge utilization also suggests that in discussing the DCDC research with their peers, policy makers may become aware of salient research projects and these discussions may also enhance perceptions of the legitimacy, saliency, and credibility of the information provided. Such peer-to-peer contacts may thus be vital for the external reputation of an organization and may be an important factor in its success or failure, as illustrated in other organizational contexts (Carmeli and Cohen 2001, Carmeli and Tishler 2005). This is one of the first analyses to reveal these important findings and it should be viewed as a starting point for developing more sophisticated understanding of the effects of social interactions and social networks on adaptive governance in bridging organizations.
We examined if and how the organization was successful in providing a productive neutral space in which divergent organizational interests and cultural barriers could be ameliorated, and the social networks fostered. We also examined the use of boundary objects and the key role of brokering individuals in promoting learning. Finally, we assessed the degree to which power relations among stakeholders served by the bridging organization shaped learning (Fig. 2).

In brief, we found that depoliticized arenas created by DCDC appeared to have contributed to both lowering cultural barriers between stakeholder groups and aligning their interests, while significantly fostering the growth of social networks and increasing interaction among stakeholders. Boundary objects also helped to align stakeholder interests and enhance learning, but only via active facilitation by key liaisons brokering between the divergent interests of bridging organization stakeholder groups. This illustrates the importance of such strategic roles for enhancing bridging organization capacity to manage divergent stakeholder interests and navigate power differentials among them to successfully catalyze learning in support of natural resource governance (cf. Olsson et al. 2007).

Reflecting on our suggested methodology, a few points merit further discussion. First, regarding the knowledge utilization approach, our suggested analysis is based on the notion that it is the individual who incorporates something into his/her stock of knowledge before s/he chooses to incorporate it into new practices, policies, etc. However, the incorporation of new understanding into an official policy or a guideline for practice is a form of organizational learning. The knowledge utilization approach to operationalizing and measuring this aspect of learning thus has the potential to address both levels ${ }^{[3]}$, which is important because both individual and organization learning contribute to more effective natural resource governance (Fazey et al. 2005). Another strength of this approach is that when combined with other quantitative methods, such as formal networks analysis, it becomes possible to assess the degree to which strategies often claiming to be a key function of bridging organizations, such as network building, actually resulted in improved learning. Still, as the above analyses demonstrate, quantitative metrics should ideally be combined with qualitative methods to fully understand the underlying social processes and mechanisms by which knowledge is transferred across and within social groups, as well as to understand the environmental conditions that can facilitate or stymie this transfer and use. Furthermore, measuring knowledge utilization among each stakeholder group will require applying this approach to each group participating in the bridging organization rather than only resource managers (as we have). For example, it is equally important to understand the degree to which academics learn and utilize information from policy makers. The scale currently focuses 
on incorporation of new knowledge into public policy, and would therefore have to be adapted to account for the fact that knowledge utilization might occur in different ways depending on whether an actor or group works in public policy, as a practitioner such as land manager, as an academic researcher, or as a natural resource user.

Second, more work is needed to measure feedbacks surrounding learning in bridging organizations. As different stakeholders incorporate new forms of knowledge into policies and practices they change the system they manage as well as how users relate to it. It is therefore important to understand how users relate to these transformations and change their actions as a result. Our use of knowledge utilization as proxy for learning will not adequately capture this dynamic process and more work is required to conceptualize and measure these more transformative aspects of learning.

Third, our overview of the socio-environmental conditions that facilitate knowledge utilization should be viewed as a general framework outlining some of the conditions that have been identified in the literature as supporting knowledge utilization in bridging organizations. There are likely other factors that facilitate knowledge utilization, and it is probable that some of these will be context specific. Still, the conditions identified here provide an important starting point for data collection, analysis, and beginning to erect a general understanding of the conditions under which knowledge utilization occurs in bridging organizations and the extent to which it can contribute to effective adaptive natural resource governance.

Finally, just as natural resources need to be managed adaptively, so knowledge utilization needs to be continuously measured and assessed. Our analysis represents a snapshot of an organization and how it promotes learning, but more dynamic analyses of changes in social networks and organizational environments over time would present a more realistic depiction of knowledge transfer and utilization. Such analyses would require longitudinal data sets that can be time consuming to amass but that hold great promise in revealing how factors highlighted in our framework interact over time to affect learning for adaptive governance. We see the framework proposed here as a starting point of a broader research agenda to design a robust methodology to systematically assess learning in adaptive governance. We acknowledge its limitations and hope that this research can trigger some fruitful discussions on how to move this important research agenda forward in the future.

Responses to this article can be read online at: http://www.ecologyandsociety.org/vol17/issl/art32/ responses/

\section{Acknowledgments:}

The authors would like to acknowledge all of the DCDC researchers, water policy community members, and Arizona State University administrators and employees for their time and support of this project. This research was funded by National Science Foundation grant SES-0345945, as well as the Swedish Research Council Formas (Crona Assistant Professorship), and MISTRA (through a core grant to the Stockholm Resilience Centre). Any opinions, findings, conclusions, or recommendation are those of the authors and do not necessarily reflect the view of the funding bodies.

\section{LITERATURE CITED}

Adler, P. S., and S. W. Kwon. 2002. Social capital: prospect for a new concept. Academy of Management Review 27:17-40.

Allan, C., A. Curtis, G. Stankey, and B. Shindler. 2008. Adaptive management and watersheds: a social science perspective. Journal of the American Water Resources Association 44(1):166-174. http://dx.doi.org/10.1111/j.17521688.2007.00145.X

Altheide, D. L. 1996. Qualitative media analysis. Sage, Thousand Oaks, California, USA.

Armitage, D., M. Marschke, and R. Plummer. 2008. Adaptive co-management and the paradox of learning. Global Environmental Change 18(1):86-98. http://dx.doi.org/10.1016/ j.gloenvcha.2007.07.002

Ayles, B. G., R. Bell, and A. Hoyt. 2007. Adaptive fisheries co-management in the western Canadian Arctic. Pages 125-150 in D. Armitage, F. Berkes, and N. C. Doubleday, editors. Adaptive co-management: collaboration, learning, and multi-level governance. University of British Columbia Press, Vancouver, British Columbia, Canada.

Backer, T. E. 1991. Knowledge utilization. Knowledge: Creation, Diffusion, Utilization 12(3):225-240.

Bandura, A. 1977. Social learning theory. Prentice-Hall, Englewood Cliffs, New Jersey, USA.

Berkes, F. 2007. Community-based conservation in a globalized world. Proceedings of the National Academy of Sciences 104(39):15188-15193. http://dx.doi.org/10.1073/pn as.0702098104

Berkes, F. 2009. Evolution of co-management: role of knowledge generation, bridging organizations and social learning. Journal of Environmental Management 90:1692-1702. http://dx.doi.org/10.1016/j.jenvman.2008.12.001

Berkes, F., N. Bankes, M. Marschke, D. Armitage, and D. Clark. 2005. Cross-scale institutions and building resilience in the Canadian North. Pages 225-247 in F. Berkes, R. Huebert, 
H. Fast, M. Manseau, and A. Diduck, editors. Breaking ice: renewable resource and ocean management in the Canadian North. University of Calgary Press, Calgary, Alberta, Canada.

Bodin, Ö., and B. I. Crona. 2009. The role of social networks in natural resource governance: what relational patterns make a difference? Global Environmental Change 19:366-374. htt p://dx.doi.org/10.1016/j.gloenvcha.2009.05.002

Booth, T. 1990. Researching policy research: issues of utilization in decision making. Science Communication 12 (1):80-100. http://dx.doi.org/10.1177/107554709001200106

Borgatti, S. P., M. G. Everett, and L. C. Freeman. 2002. Ucinet for windows: software for social network analysis. Analytic Technologies, Lexington, Kentucky, USA.

Brown, L. D. 1991. Bridging organizations and sustainable development. Human Relations 44:807-831. http://dx.doi.org /10.1177/001872679104400804

Brown, L. D. 1993. Development bridging organizations and strategic management of social change. Institute for Development Research Reports Vol. 10.3. IDR, Boston, Massachusetts, USA.

Caplan, N. 1979. The two communities theory and knowledge utilization. American Behavioral Scientist 22(3):459-470. http://dx.doi.org/10.1177/000276427902200308

Carmeli, A., and A. Cohen. 2001. Organizational reputation as a source of sustainable competitive advantage and above normal performance: an empirical test among local authorities in Israel. Public Administration \& Management: An Interactive Journal of Applied Corporate Finance 6 (4):122-165.

Carmeli, A., and A. Tishler. 2005. Perceived organizational reputation and organizational performance: an empirical investigation of industrial enterprises. Corporate Reputation Review 8(1):13-30. http://dx.doi.org/10.1057/palgrave.crr.1540236

Carr, A., and R. Wilkinson. 2005. Beyond participation: boundary organizations as a new space for farmers and scientists to interact. Society \& Natural Resources 18:255-265. http://dx.doi.org/10.1080/08941920590908123

Cash, D. W., W. C. Clark, F. Alcock, N. M. Dickson, N. Eckley, D. Guston, J. Jager, and R. B. Mitchell. 2003. Knowledge systems for sustainable development. Proceedings of the National Academy of Sciences 100(14):8086-8091. htt p://dx.doi.org/10.1073/pnas.1231332100

Crona, B., and J. Parker. 2009. All things to all people: an assessment of DCDC as a boundary organization. Arizona State University, Phoenix, Arizona, USA.
Crona, B., and J. Parker. 2011. Network determinants of knowledge utilization: preliminary lessons from a boundary organization. Science Communication 33(4):448-471. http:// dx.doi.org/10.1177/1075547011408116

Crona, B., and Ö. Bodin. 2006. What you know is who you know? Communication patterns among resource users as a prerequisite for co-management. Ecology and Society 11(2): 7. [online] URL: http://www.ecologyandsociety.org/vol11/iss2/ $\underline{\operatorname{art} 71}$

Eamer, J. 2006. Keep it simple and be relevant: the first ten years of the Arctic Borderlands Ecological Knowledge Coop. Pages 185-206 in W. V. Reid, F. Berkes, T. Wilbanks, and D. Capistrano, editors. Bridging scales and knowledge systems. Millennium Ecosystem Assessment and Island Press, Washington, D.C., USA.

Fazey, I., J. A. Fazey, and D. M. A. Fazey. 2005. Learning more effectively from experience. Ecology and Society 10(2): 4. [online] URL: http://www.ecologyandsociety.org/vol10/iss2/ $\underline{\operatorname{art} 4 /}$

Folke, C., T. Hahn, P. Olsson, and J. Norberg. 2005. Adaptive governance of social-ecological systems. Annual Review of Environment and Resources 30:441-473. http://dx.doi.org/10 .1146/annurev.energy.30.050504.144511

Freeman, R. E. 1984. Strategic management: a stakeholder approach. Pitman, Boston, Massachusetts, USA.

Frenk, J. 1992. Balancing relevance and excellence: organizational response to link research with decision making. Social Science \& Medicine 35(11):1397-1404. http://dx.doi.o rg/10.1016/0277-9536(92)90043-P

Fujimura, J. 1992. Crafting science: standardized packages, boundary objects and "translation". Pages 168-211 in A. Pickering, editor. Science as culture and practice. University of Chicago Press, Chicago, Illinois, USA.

Gano, G. L., J. E. Crowley, and D. Guston. 2007. 'Shielding' the knowledge transfer process in human service research. Journal of Public Administration 17:39-60.

Gober, P. 2006. Metropolitan Phoenix. Place making and community building in the desert. University of Pennsylvania Press, Philadelphia, Pennsylvania, USA.

Gober, P., C. W. Kirkwood, R. C. Balling, Jr., A. W. Ellis, and S. Deitrick. 2010. Water planning under climatic uncertainty in Phoenix: why we need a new paradigm. Annals of the Association of American Geographers 100(2):356-372. http://dx.doi.org/10.1080/00045601003595420

Gray, B., and D. J. Wood. 1991. Collaborative alliances: moving from practice to theory. Journal of Applied Behavioral Science 27(1):3-22. http://dx.doi.org/10.1177/0021886391271001 
Guston, D. H. 1999. Stabilizing the boundary between US politics and science: the role of the office of technology transfer as a boundary organization. Social Studies of Science 29:87-111. http://dx.doi.org/10.1177/030631299029001004

Guston, D. H. 2001. Boundary organizations in environmental policy and science: an introduction. Science Technology and Human Values 26(4):399-408. http://dx.doi.org/10.1177/0162 24390102600401

Hackett, E. J., and J. N. Parker. 2012. Research groups. Pages 165-174 in W. S. Bainbridge, editor. Leadership in science and technology: a reference handbook. Sage, Thousand Oaks, California, USA.

Hahn, T., P. Olsson, C. Folke, and K. Johansson. 2006. Trustbuilding, knowledge generation and organizational innovations: the role of a bridging organization for adaptive comanagement of a wetland landscape around Kristianstad, Sweden. Human Ecology 34(4):573-592. http://dx.doi.org/10 $.1007 / \mathrm{s} 10745-006-9035-\mathrm{Z}$

Knott, J., and A. Wildavsky. 1980. If dissemination is the solution, what is the problem? Knowledge: Creation, Diffusion and Utilization 4:537-578.

Kolb, D. A. 1984. Experiential learning: experience as the source oflearning and development. Prentice Hall, Engelwood Cliffs, New Jersey, USA.

Lach, D., P. List, B. Steel, and B. Schindler. 2003. Advocacy and credibility of ecological scientists in resource decisionmaking: a regional study. BioScience 53(2):170-178. http://dx.doi.org/10.1641/0006-3568(2003)053[0170:AACOES] 2.0.CO;2

Landry, R., N. Amara, and M. Ouimet. 2007. Determinants of knowledge transfer: evidence from Canadian university researchers in natural sciences and engineering. Journal of Technology Transfer 32:561-592. http://dx.doi.org/10.1007/s1 0961-006-0017-5

Landry, R., M. Lamari, and N. Amara. 2003. The extent and the determinants of the utilization of university research in government agencies. Public Administration Review 63 (2):191-205. http://dx.doi.org/10.1111/1540-6210.00279

Lawrence, T. B., and C. Hardy. 1999. Building bridges for refugees: toward a typology of bridging organizations. Journal of Applied Behavioral Science 35(1):48-70. http://dx.doi.org/ $\underline{10.1177 / 0021886399351006}$

Lomas, J. 1997. Research and evidence-based decision making. Australian and New Zealand Journal of Public Health 21(5):439-441. http://dx.doi.org/10.1111/j.1467-842X.1997.t b01730.x
Ludwig, D. 2001. The era of management is over. Ecosystems 4:758-764. http://dx.doi.org/10.1007/s10021-001-0044-x

McNie, E.C. 2007. Reconciling the supply of scientific information with user demands: an analysis of the problem and review of the literature. Environmental Science \& Policy 10:17-38. http://dx.doi.org/10.1016/j.envsci.2006.10.004

Mezirow, J., and associates. 2000. Learning as transformation: critical perspectives on a theory in progress. Jossey-Bass, San Francisco, California, USA.

Miller, C. 2001. Hybrid management: boundary organizations, science policy, and environmental governance in the climate regime. Science, Technology, \& Human Values 26(4):478-500. http://dx.doi.org/10.1177/016224390102600405

Mitchell, R. K., B. R. Agle, and D. J. Wood. 1997. Toward a theory of stakeholder identification and salience: defining the principle of who and what really counts. Academy of Management Review 22(4):853-886. http://dx.doi.org/10.230 $\underline{7 / 259247}$

Morse, R. S. 2010. Bill Gibson and the art of leading across boundaries. Public Administration Review 70(3):434-442. http://dx.doi.org/10.1111/j.1540-6210.2010.02157.x

Muro, M., and P. Jeffrey. 2008. A critical review of the theory and application of social learning in participatory natural resource management processes. Journal of Environmental Planning and Management 51(3):325-344. http://dx.doi.org/1 $\underline{0.1080 / 09640560801977190}$

Nahapiet, J., and S. Ghoshal. 1998. Social capital, intellectual capital, and the organizational advantage. Academy of Management Review 23:242-266.

Oh, C. H., and R. F. Rich. 1996. Explaining use of information in public policymaking. Knowledge, Technology \& Policy 9:3-35. http://dx.doi.org/10.1007/BF02832231

Olsson, P., C. Folke, V. Galaz, T. Hahn, and L. Schultz. 2007. Enhancing the fit through adaptive co-management: creating and maintaining bridging functions for matching scales in the Kristianstads Vattenrike Biosphere Reserve, Sweden. Ecology and Society 12(1): 28. [online] URL: http://www.ecologyand society.org/vol12/iss1/art28/

Olsson, P., C. Folke, and T. Hahn. 2004. Social-ecological transformation for ecosystem management: the development of adaptive co -management of a wetland landscape in southern Sweden. Ecology and Society 9(4): 2. [online] URL: http://www.ecologyandsociety.org/vol9/iss4/art2/

Olsson, P., C. Folke, and F. Berkes. 2004. Adaptive comanagement for building resilience in social-ecological systems. Environmental Management 34(1):75-90. http://dx.d oi.org/10.1007/s00267-003-0101-7 
Olsson, P., L. H. Gunderson, S. R. Carpenter, P. Ryan, L. Lebel, C. Folke, and C. S. Holling. 2006. Shooting the rapids: navigating transitions to adaptive governance of socialecological systems. Ecology and Society 11(1): 18. [online] URL: http://www.ecologyandsociety.org/vol11/iss1/art18/

Orlandi, M. 1996. Health promotion technology transfer: organizational perspectives. Canadian Journal of Public Health 87(2):28-33.

Pahl-Wostl, C., M. Craps, A. Dewulf, E. Mostert, D. Tabara, and T. Taillieu. 2007. Social learning and water resources management. Ecology and Society 12(2): 5. [online] URL: http://www.ecologyandsociety.org/vol12/iss2/art5/

Pahl-Wostl, C., D. Tàbara, R. Bouwen, M. Craps, A. Dewulf, E. Mostert, D. Ridder, and T. Taillieu. 2008. The importance of social learning and culture for sustainable water management. Ecological Economics 64:484-495. http://dx.do i.org/10.1016/j.ecolecon.2007.08.007

Parker, J., and B. Crona. 2012. On being all things to all people: boundary organizations \& the contemporary research university. Social Studies of Science 42(2):262-289. http://dx .doi.org/10.1177/0306312711435833

Piaget, J. 1985. The equilibration of cognitive structures: the central problem of intellectual development. University of Chicago Press, Chicago, Illinois, USA.

Quay, R. 2004. Bridging the gap between ecological research and land use policy: the North Sonoran collaboration. Urban Ecosystems 7:283-294. http://dx.doi.org/10.1023/B:UECO.00 00044040.89829.08

Reed, M. S., A. C. Evely, G. Cundill, I. Fazey, J. Glass, A. Laing, J. Newig, B. Parrish, C. Prell, C. Raymond, and L. C. Stringer. 2010. What is social learning? Ecology and Society 15(4): r1. [online] URL: http://www.ecologyandsociety.org/vol15/ iss4/resp1/

Rich, R. 1997. Measuring knowledge utilization process and outcomes, knowledge and policy. International Journal of Knowledge Transfer and Utilization 10(3):3-10.

Rist, L., M. Chidambaranathan, C. Escobar, U. Wiesmann, and A. Zimmerman. 2007. Moving from sustainable management to sustainable governance of natural resources: the role of social learning process in rural India. Journal of Rural Studies 23:23-37. http://dx.doi.org/10.1016/j.jrurstud.2 $\underline{006.02 .006}$

Rockström, J., W. Steffen, K. Noone, Å. Persson, F. S. Chapin, III, E. F. Lambin, T. M. Lenton, M. Scheffer, C. Folke, H. J. Schellnhuber, B. Nykvist, C. A. de Wit, T. Hughes, S. van der Leeuw, H. Rodhe, S. Sörlin, P. K. Snyder, R. Costanza, U. Svedin, M. Falkenmark, L. Karlberg, R. W. Corell, V. J. Fabry, J. Hansen, B. Walker, D. Liverman, K. Richardson, P. Crutzen, and J. A. Foley. 2009. A safe operating space for humanity. Nature 461(7263):472-475. http://dx.doi.org/10.1038/461472a

Rod, M. R. M., and S. J. Paliwoda. 2003. Multi-sector collaboration: a stakeholder perspective on a government, industry and university collaborative venture. Science and Public Policy 30:273-284. http://dx.doi.org/10.3152/1471543 $\underline{03781780399}$

Schultz, L., C. Folke, and P. Olsson. 2007. Enhancing ecosystem management through social-ecological inventories: lessons from Kristianstad Vattenrike, Sweden. Environmental Conservation 34(2):140-152. http://dx.doi.org/10.1017/S0376 $\underline{892907003876}$

Schusler, T. M., D. J. Decker, and M. J. Pfeffer. 2003. Social learning for collaborative natural resource management. Society \& Natural Resources 16(4):309-326. http://dx.doi.org $\underline{110.1080 / 08941920309158}$

Selsky, J. W., and B. Parker. 2005. Cross-sector partnerships to address social issues: challenges to theory and practice. Journal of Management 31(6):849-873. http://dx.doi.org/10.1 $\underline{177 / 0149206305279601}$

Sharma, S., H. Vredenburg, and F. Westley. 1994. Strategic bridging: a role for the multinational corporation in third world development. Journal of Applied Behavioral Science 30 (4):458-476. http://dx.doi.org/10.1177/0021886394304007

Stafford, E. R., M. J. Polonsky, and C. L. Hartman. 2000. Environmental NGO-business collaboration and strategic bridging: a case analysis of the Greenpeace-Foron alliance. Business Strategy and the Environment 9:122-135. http://dx.d oi.org/10.1002/(SICI)1099-0836(200003/04)9:2<122::AIDBSE232>3.0.CO;2-C

Star, S. L., and J. R. Griesemer. 1989. Institutional ecology, 'translations' and boundary objects: amateurs and professionals in Berkley's Museum of Vertebrate Zoology, 1907-1939. Social Studies of Science 19(3):387-420. http://dx doi.org/10.1177/030631289019003001

Steel, B. S., D. Lach, and V. A. Satyal. 2006. Ideology and scientific credibility: environmental policy in the American Pacific Northwest. Public Understanding of Science 15:481-495. http://dx.doi.org/10.1177/0963662506059261

Steel, B. S., R. L. Warner, and D. Lach. 2010. Gender differences in support for scientific involvement in US environmental policy. Science, Technology, \& Human Values 35(2):147-173. http://dx.doi.org/10.1177/0162243909340259

Webber, D. J. 1992. The distribution and use of policy knowledge in the policy process. Knowledge, Technology \& Policy 4(4):6-35. http://dx.doi.org/10.1007/BF02692779 
Wenger, E. 1998. Communities of practice: learning, meaning and identity. Cambridge University Press, Cambridge, UK.

Westley, F., and H. Vredenburg. 1991. Strategic bridging: the collaboration between environmentalists and business in the marketing of green products. Journal of Applied Behavioral Science 27(1):65-90. http://dx.doi.org/10.1177/0021886391271004

White, D. D., A. Wutich, K. L. Larson, P. Gober, T. Lant, and C. Senneville. 2010. Credibility, salience, and legitimacy of boundary objects: water managers' assessment of a simulation model in an immersive decision theater. Science and Public Policy 37(3):219-232. http://dx.doi.org/10.3152/030234210X $\underline{497726}$

Yip, J., S. Wong, and C. Ernst. 2008. The nexus effect: when leaders span group boundaries. Leadership In Action 28 (4):13-17. http://dx.doi.org/10.1002/lia.1256

${ }^{[1]}$ Cash et al. (2003) use the term 'saliency' rather than 'relevance.' We have opted for the latter to avoid terminological confusion in relation to the stakeholder theory of saliency.

${ }^{[2]}$ We also tested the effects of a policy maker's position within the overall social network created by the bridging organization (betweeness-centrality) for knowledge utilization, but no significant relationships were found.

${ }^{[3]}$ Organizational learning, as defined here, would thus be captured through those individuals who score the highest level (level 5: DCDC research results influence decisions in my administrative unit) on the knowledge utilization scale (see Appendix 1.1). 


\section{APPENDIX 1: Survey items for attitudinal and network data collection}

1. Knowledge Utilization Scale (adapted from Knott and Wildavsky 1980 and Landry et al 2003)

Stage 1: I receive DCDC research pertinent to my work.

( 0 =Does not apply, $1=$ Never, 2 = Rarely, $3=$ Sometimes, $4=$ Usually, $5=$ Always $)$

Stage 2: I understand the DCDC research that I receive.

( 0 =Does not apply, $1=$ Never, $2=$ Rarely, $3=$ Sometimes, $4=$ Usually, $5=$ Always $)$

Stage 3: I cite DCDC as references in my own professional reports or documents. ( 0 =Does not apply, 1 = Never, $2=$ Rarely, $3=$ Sometimes, $4=$ Usually, $5=$ Always $)$

Stage 4: I make efforts to favour the use of DCDC research results.

( 0 =Does not apply, $1=$ Never, $2=$ Rarely, $3=$ Sometimes, $4=$ Usually, $5=$ Always $)$

Stage 5: DCDC research results influence decisions in my administrative unit.

( 0 =Does not apply, $1=$ Never, $2=$ Rarely, $3=$ Sometimes, $4=U$ Usually, $5=$ Always $)$

2. Cultural Differences (adapted from Gano et al 2007)

How important do you perceive the following items to be in terms of influencing members of the policy community about whether to use [DCDC] research?

Scientific merit

$(1$ = Very Important, 2 = Somewhat Important, 3 = Neutral, 4 = Somewhat unimportant, 5 = Very Unimportant)

Strong experimental design of studies producing the scientific information $(1$ = Very Important, 2 = Somewhat Important, 3 = Neutral, 4 = Somewhat unimportant, $5=$ Very Unimportant)

Strong inter-personal contacts between policy makers and [borg] members (1 = Very Important, 2 = Somewhat Important, 3 = Neutral, 4 = Somewhat unimportant, 5 = Very Unimportant)

Clear dissemination strategy from [DCDC] to the policy community (1 = Very Important, 2 = Somewhat Important, 3 = Neutral, 4 = Somewhat unimportant, 5 = Very Unimportant)

The following questions are designed to assess differences in the types of interaction that occur between DCDC members and the policy community. For the purposes of this study we define passive interaction as acquiring information from DCDC without discussing its content with a DCDC member (For example, receiving data sets or maps from a 
DCDC member without discussing their content). Active interaction is defined as having meaningful discussions with DCDC members about the content of DCDC research.

\section{Direct interactions}

Please list the five people at DCDC with whom you have the most interaction about DCDC related research. If fewer than five, list all that apply.

\section{Indirect interactions}

Please list the five people in the policy and water management community with whom you discuss DCDC research the most. If fewer than five, list all that apply. 


\section{APPENDIX 2: Details of the statistical model for measuring the effect of social relations on knowledge utilization}

We used multiple hierarchical regression to test the degree to which two different types of social relations affected knowledge utilization. This means we treated the two different measures of social interaction as independent variables and correlated them with the total knowledge utilization score for each policy maker (the dependent variable). This was done in two steps. The first regression model (Model 1 in Table B-1) included the total number of direct contacts each policy maker had with DCDC researchers. Next (Model 2), we included the total number of other policy makers with whom each discusses DCDC coproduced research. We also tested the effects of occupying the shortest distance in the overall network (i.e. betweenness centrality) for knowledge utilization but no significant relationship was found.

Table 2.1

\begin{tabular}{|l|l|l|l|l|l|l|}
\hline $\mathrm{N}=32$ & \multicolumn{2}{|l|}{$\begin{array}{l}\text { Model 1 } \\
\mathrm{r}^{2}=0.133, \text { Adj. } \mathrm{r}^{2}=0.104, \mathrm{~F}=4.588\end{array}$} & \multicolumn{2}{l|}{$\begin{array}{l}\text { Model 2 } \\
\mathrm{r}^{2}=0.307, \text { Adj. } \mathrm{r}^{2}=0.260, \mathrm{~F} \text { change=7.317 }\end{array}$} \\
\hline & Beta & Std. Error & Std. Beta & Beta & Std. Error & Std. Beta \\
\hline Direct interactions & 7.803 & 3.643 & $0.364^{* *}$ & 7.350 & 3.315 & $0.343^{* *}$ \\
\hline Indirect interactions & & & & 4.062 & 1.502 & $0.419^{* *}$ \\
\hline
\end{tabular}

${ }^{*} \mathrm{p}<.1 ;{ }^{* *} \mathrm{p}<.05$ (two-tailed tests) 